\title{
Reviewing Non-Linear Micro-artefacts' Structure
}

\author{
Dimitris Kontogiorgos*
}

Wiener Laboratory, American School of Classical Studies at Athens, 6 Souidias Str., 10676 Athens, Greece

\begin{abstract}
This paper reviews the implementation of a non-linear method, the spherical self- organising feature map that was able to recognise non-linear patterns in micro-artefacts, proposing the necessity for such recognitions in order to improve archaeological interpretations.
\end{abstract}

Keywords: Micro-artefacts, non-linearity, spherical self- organising feature map, pattern recognition.

\section{INTRODUCTION}

Micro-artefacts (i.e., cultural particles smaller than $2 \mathrm{~mm}$ in diameter), due to their abundance and incorporation into the sedimentary matrix of an archaeological deposit, constitute a significant part of the cultural particles present [1]. Micro-artefact analysis is extensively complex due to the different micro-artefact categories that may appear in an archaeological context and also because of the numerous cultural (and non-cultural/natural) formation processes that may have been involved in the creation of characteristics specific to an archaeological context.

Recently, the implementation of a non-linear method (i.e., spherical-SOFM) on micro-artefact data has shown that the method is able to recognise and to provide a visual representation of micro-artefact patterns prior to performing any statistical analysis on the data, providing a quick view into possible relationships or differences that may occur between temporally, spatially, and culturally different archaeological contexts (i.e., pits and ditches from a Neolithic Tell site which unusually comprises an extended settlement component in N Greece) [2]. It was shown that the spherical-SOFM non-linear method revealed patterns among the data that linear methods were unable to classify. Furthermore, the method attempted to overcome the difficulties posed by the friable nature of different micro-artefact classes (for example, unburnt clay, burnt clay, bone, shell, or charcoal). Material characteristics and the process of micro-artefact generation, including the effects of post-depositional processes, were considered as important factors in the search for strong pattern recognition [3]. The analysis has shown that similar classes of micro-artefacts in three analyzed data sets were characterised by different non-linear associations, further suggesting that these were possibly formed through different cultural formation processes [2].

The implementation of the spherical-SOFM non-linear method was also able to recognise and to provide a visual representation of micro-artefact patterns in archaeological contexts (i.e., a colluvial deposit from a Hellenistic Theatre in NW Greece) affected only by natural formation processes

Address correspondence to this author at the Wiener Laboratory, American School of Classical Studies at Athens, 6 Souidias Str., 10676 Athens, Greece; Tel: (+30) 213000 2400; Fax: (+30) 210725 0584;

E-mail: mitsaraskonto@hotmail.com
[4, 5]. Section 2 briefly describes how the spherical selforganizing map creates a 3D visual or graphical representation of the data. Section 3 reviews the implementation of the method arguing for the necessity for such recognitions in archaeological analysis in order to improve interpretation while section 4 offers the concluding remarks.

\section{SPHERICAL SELF-ORGANIZING FEATURE MAP}

The Spherical Self-Organizing Feature Map (S-SOFM), introduced by Kohonen [6], maps n-dimensional data into a low-dimensional space. The spherical SOFM [7] the lowdimensional space is a tessellated sphere that is formed by subdividing an icosahedron. Every vertex on this sphere is a strategic location of an n-dimensional vector that represents an ensemble of similar data vectors which are assigned to the vector during the mapping operation. It is therefore necessary to visually enhance variations in the data using the physical attributes of the mapping lattice. The benefit of a spherical lattice in the implementation of the S-SOFM is that the enclosed space can be used to generate a $3 \mathrm{D}$ visual representation of some physical aspects of the n-dimensional data.

Conventional implementation of the S-SOFM method has used a 2D lattice as the low-dimensional space, and associations in the data are visualised by means of a terrain map, wherein elevation represents some aspects of the vector(s) at that location [8, 9]. Relative similarity between data vectors mapped into the sphere can be visualised by introducing distortions in the sphere accompanied by changes in the colour. Informative characteristics of the data are reflected as distortions and colour gradations on the surface of the sphere. The formulation of these measures is a non-trivial task and often application dependent. The measures reflect desired data correlations (either linear or non-linear) and must be defined by the researcher who is familiar with the underlying data set. It is this aspect of the S-SOFM that differs from existing literature about the self-organising feature map. The S-SOFM utilises the spherical lattice of the SSOFM space to generate a visual form of the clustered data that is more intuitive and easy to perceive. A visual form of the data is created by scaling the radial distance of the vertices on the sphere in proportion to a measure characterising some physical aspects of the data. Examples illustrating the various implementations of the spherical SOFM on different data and the use of possible measures to create spherical 
SOFM graphical representations are discussed in Sangole [7] and Sangole and Knopf [10].

\section{A REVIEW OF THE IMPLEMENTATION OF SPHERICAL SELF-ORGANISING FEATURE MAP (S- SOFM) IN MICRO-ARTEFACT ANALYSIS}

The Spherical Self-Organising Feature Map (S-SOFM), was for the first time applied in the analysis of microartefacts in selected deposit from a Neolithic Tell/extended settlement in northern Greece (i.e., pits and ditches of the Neolithic period while pits of the Byzantine/Ottoman period were also analysed for comparative purposes) [2].

Micro-artefacts provide different information than do larger artefacts and definitely should not be used simply to reflect 'noise' in larger artefacts [e.g., 11]. Therefore, the researcher cannot assume that, for example, chronologically distant archaeological contexts, as those used in the previously mentioned study [2], will provide similar or different micro-artefact patterning due to the many factors that may account for the observed pattern. The non-linear method overcomes these difficulties by identifying patterns of microartefacts' not easily detected by conventional plotting methods. The implication is that it enhanced attempts for developing interpretations on micro-artefact patterning by providing strong pattern recognition [3].

The construction of the S-SOFM graphical representation was based on a database of 250 five-dimensional records each dimension representing a micro-artefact category (i.e., micro-shell, micro-bone, micro-fragments of charcoal, micro-fragments of burnt clay, and micro-fragments of unburnt clay). Every row represented the point counting results [2]. A spherical-SOFM graphical representation was created as described in Sangole [7], Sangole and Knopf [10] and Leontitsis and Sangole [12].

Figs. (1) and (2) present the S-SOFM graphical representation resulted from the micro-artefact database and compris-

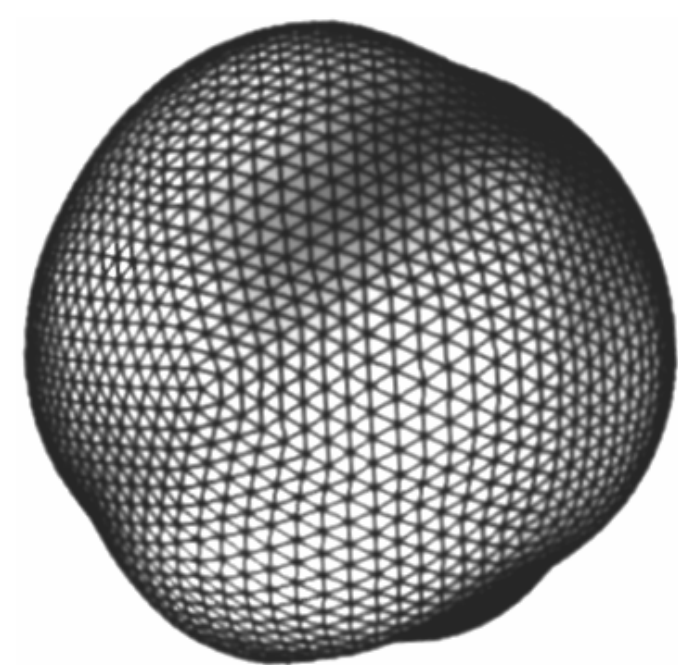

Fig. (1). One view of the S-SOFM graphical representation showing the formation of two distinct white regions - the larger (bottomright) corresponds to the Neolithic micro-artefact data, and the smaller (top- left) corresponds to the Byzantine-Ottoman microartefact data (after Kontogiorgos, 2008), Fig. (4.1). ing the results obtained from point-counting. Fig. (1) shows a formation of two distinct white regions that correspond to the data from the Neolithic and Byzantine/Ottoman contexts from the tell component of the site while in Fig. (2) the white area corresponds to the data from the Neolithic contexts from the extended component of the site. These results have put grounds to suggest that the Neolithic contexts from the tell and the extended part of the site as well as the Byzantine/Ottoman contexts were possibly characterised by different multivariate distributions. A non-linear structure lies within this statistical space which can be distinguished into three separate sub-structures. The spherical-SOFM pattern recognition procedure provided a comprehensive preliminary visual representation of inherent non-linear characteristics in data, serving as the initial step in the analysis of the multidimensional micro-artefact data. Three meaningful components were revealed - Neolithic contexts on the tell, Neolithic from the extended part of the site, and Byzantine/Ottoman contexts, which appeared to be the determinants for the constitution of the analysed data set [2].

This further suggested that the three groups of contexts from the site were possibly formed through different formation processes. It is important to mention that the five classes of micro-artefacts set for analysis (i.e., micro-shell, microbone, micro-fragments of charcoal, micro-fragments of burnt clay, and micro-fragments of unburnt clay) generate from an interpretatively complicated set of larger artefacts, those made of friable materials -the so called 'size unstable' [13]. The preservation of such materials in an archaeological context indeed, is closely connected not only with the length of deposition but also with the rate and type of weathering [13].

Despite these difficulties the non-linear method revealed that the archaeological contexts from the Neolithic site exhibit strong spatial patterning. The observation of this pattern in cultural indicators such as micro-artefacts was related at least in part (and arguably for the most part) with differences in the spatial organisation of activities carried out in the site

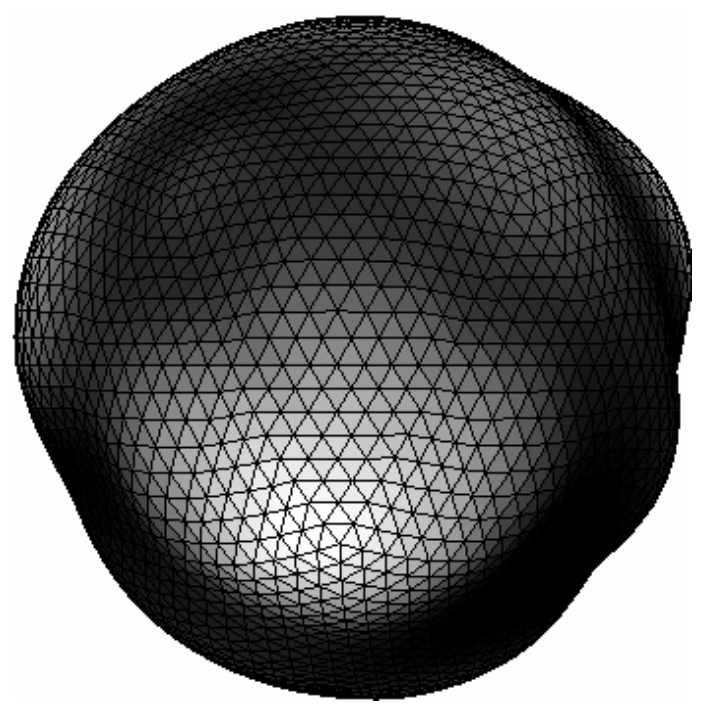

Fig. (2). Second view of the S-SOFM graphical representation showing the formation of one distinct white region corresponding to the Neolithic micro-artefact data from the extended part of the site (after Kontogiorgos, 2008), Fig. (4.2). 
and ending up in the deposits. In other words, it was related with spatial differences in cultural formation processes [2].

The spherical self-organising feature map was also implemented on micro-artefact data from the colluvial deposit, covering the theatre of the Hellenistic period, located outside the city walls of the Hellenistic city of Gitana in the Thesprotia region-Epirus-NW Greece that was shaped only by the effects of natural formation processes $[4,5]$.

The construction of the S-SOFM graphical representation was based on a database of 44 three-dimensional records, each dimension representing a micro-artefact category (i.e., micro-shell, micro-bone, burnt clay). Every row represented the point-counting results [5]. Three views of the resulting SSOFM graphical representation are illustrated in Fig. (3) showing the formation of a distinct black region attributed to the ability of natural formation processes to create patterns in micro-artefacts. This result was consistent with a detailed geo-archaeological analysis of the colluvial deposit which has shown concentration (i.e., peaks) of micro-artefacts in fine sediment attributable possibly to the effects of natural formation processes to produce such concentration of microartefacts in an archaeological deposit lacking any anthropogenic activity [4].

\section{CONCLUSION: NON-LINEARITY IN CULTURAL AND NATURAL FORMATION PROCESSES}

Since Schiffer's [14] original recognition of the importance of studying and understanding the formation processes of the archaeological record, many authors have pointed out their critical importance [e.g. 15-18]. Moreover, it is now widely accepted that variability is introduced into the archaeological record through cultural and non-cultural (natural) formation processes which distort systemic patterns as well as creating their own patterns [19]. Despite the recognised importance of cultural and natural processes in the formation of the archaeological record, studies addressing the interpretative potential of micro-artefacts remain relatively limited, although micro-artefacts, due to their abundance and incorporation in an archaeological deposit constitute a significant part of the cultural particles present and may provide information on the cultural and natural formation processes occurring in a deposit [e.g., 20-24, 11, 1].

Dunnell and Stein [11] outline some of the important characteristics of micro-artefacts that compel their consideration as archaeological data of the first order. They note, that information content may be different for micro-artefacts than for larger artefacts and they may be most informative about different things (e.g., particle transport and site formation processes). Equally important, processes that generate microscopic artefacts vary depending on material and context [11]. These last two issues, differing information content and differing formation processes within the micro-scale are important reasons for undertaking micro-artefact analysis [11]. In any case their archaeological significance rests upon understanding the interaction among, the almost, numerous variables within a sequence and stronger interpretation can only be achieved by strong micro-artefact pattern recognition especially in cases of archaeological deposits sensitive either to cultural or natural formation processes, as in the aforementioned examples.

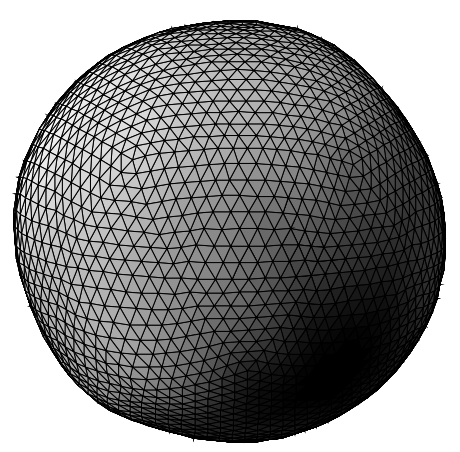

(a)

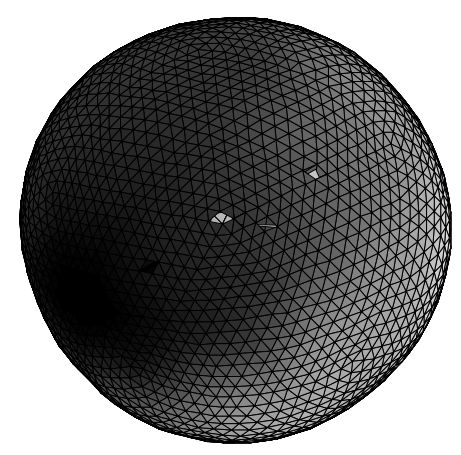

(b)

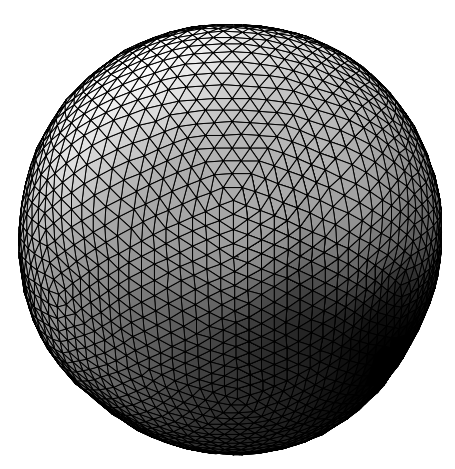

(c)

Fig. (3). Three views of the S-SOFM graphical representation showing the formation of distinct black region corresponding to the micro-artefact data (after Kontogiorgos and Leontitsis, 2011), Fig. 1 (a-c).

The implication of the applied non-linear method (i.e., spherical-SOFM) is that it has the 'ability' to demonstrate the dynamics of cultural or natural formation processes in leaving non-linear 'signals' in archaeological contexts being in a 'non equilibrium' state until the time of recovery. Therefore, the rationality for developing such recognitions in archaeological contexts is to release the dynamics of formation processes since archaeological patterning is arguably (at least 
for the most part) the result of the interplay between many complex processes, both cultural and non-cultural (natural) [25-28]. The study of micro-artefacts, although by no means conclusive, seems to preserve non-linear information on differences in cultural and/or natural formation processes arguably reflecting long-term continuity of distinct patterns of spatial organization in a non static cultural and/or physical environment.

\section{ACKNOWLEDGEMENT OF FUNDING}

None declared.

\section{CONFLICTS OF INTEREST}

None declared.

\section{REFERENCES}

[1] Sherwood SC. Microartifacts. In: Goldberg P, Holliday VT, Ferring R, Eds. Earth sciences and archaeology. New York: Kluwer Academic/ Plenum Publishers 2001; pp. 327-51.

[2] Kontogiorgos D. Geoarchaeological and microartifacts analysis of archaeological sediments. A case study from a Neolithic Tell site in Greece. New York: Nova Science Publishers Inc 2008.

[3] Kontogiorgos D, Leontitsis A, Sangole A. Telling a non linear story: The investigation of microartefacts non linear structure. $\mathrm{J}$ Archaeol Sci 2007; 34: 1532-6.

[4] Kontogiorgos D, Preka K. From neolithic to hellenistic. A geoarchaeological approach to the burial of the a hellenistic theatre: the evidence from particle size analysis and microartifacts. In: Kontogiorgos D, Ed, on site geoarchaeology on a neolithic tell site In Greece: archaeological sediments,microartifacts and softwear development. New York; Nova Science Publishers Inc. 2009: pp. 71-80.

[5] Kontogiorgos D, Leontitsis A. Is it visible? Micro-artefacts nonlinear stucture and natural formation processes In: Mivasiagi JE, Ed. self-organizing maps and novel algorithm design. Vienna, Austria: Intech open access Publishers 2011; pp.643-8.

[6] Kohonen T. Self-organized formation of topologically correct feature maps. Biol Cybern 1981; 43: 59-69.

[7] Sangole A. Data-driven modeling using spherical self-organizing feature maps. PhD dissertation. Canada, Universal Publishers; University of Western Ontanio 2003.

[8] Vesanto J. SOM-based data visualization methods. J Intell Data Anal 1999; 3: 111-26.
[9] Ultsch A, Siemon HP. Kohonen's self-organizing feature maps for exploratory data analysis. Proceedings of the International Neural Network Conference. Dordrecht, The Netherlands 1990; pp. 305-8.

[10] Sangole A, Knopf GK. Visualization of random ordered numeric data sets using self-organized feature maps. Comput Graph 2003; 27: 963-76.

[11] Dunnell RC, Stein JK. Theoretical issues in the interpretation of microartifacts. Geoarchaeology 1989; 4: 31-42.

[12] Leontitsis A, Sangole AP. Estimating an optimal neighborhood size in the spherical self-organizing feature map. Int J Comput Intell 2005; 2: 94-8.

[13] Sherwood SC, Simek JF, Polhemus RR. Artifact size and spatial process: macro- and microartifacts in a Mississipian House. Geoarchaeology 1995; 10: 429-55.

[14] Schiffer MB. Archaeological context and systemic context. Am Antiq 1972; 37; 156-65.

[15] Goldberg P, Nash DT, Petraglia MD. Formation processes in archaeological context. Madison, Wisconsin: Prehistory Press 1993.

[16] McGuire RH. Behavioural archaeology: Reflections of a prodigal son. In Skibo JM, Walker WH, Nielsen AE, Eds. Expanding archaeology. Salt Lake City: University of Utah Press 1995; pp. 162-77.

[17] Reid JJ. Four strategies after twenty years: A return to basics. In: Skibo JM, Walker WH, Nielsen AE, Eds, Expanding archaeology. Salt Lake City: University of Utah Press 1995; pp. 15-21.

[18] Tani M. Beyond the identification of formation processes: behavioural inference based on traces left by cultural formation processes. J Archaeol Method Theory 1995; 2: 231-52.

[19] Schiffer MB. Formation processes of the Archaeological record. Albuquerque: University of New Mexico Press 1987.

[20] Hassan FA. Sediments in archaeology: Methods and implications for palaeoenvironmental and cultural analysis. J Field Archaeol 1978; 5: 197-213.

[21] Fladmark KR. Microdebitage analysis: initial considerations. J Archaeol Sci 1982; 9: 205-20.

[22] Vance ED. Microdebitage and archaeological activity analysis. Archaeology 1987; 40: 58-9.

[23] Rosen AM. Cities of clay: The Geoarchaeology of tells. Chicago: University of Chicago Press 1986.

[24] Rosen AM. Ancient Town and city sites: A view from the microscope. Am Antiq 1989; 54: 564-78.

[25] Bentley RA, Maschner HDG. Complex systems and archaeology. Salt Lake City: University of Utah Press 2003.

[26] Watts DJ. Six degrees: The science of a connected age. London: Random House 2003.

[27] Ball P. Critical mass: How one thing leads to another. Portsmouth, NH: Heinemann 2004.

[28] Ormerod P. Why most things fail: Evolution, extinction, and economics. London: Faber \& Faber 2005. 